\title{
THE DIII-D RADIATIVE DIVERTOR PROJECT, STATUS AND PLANS
}

\author{
by \\ J.P. SMITH, C.B. BAXI, A.S. BOZEK, E. CHIN, M.A. HOLLERBACH, \\ W.R. JOHNSON, E.J. LAUGHON, D.G. NILSON, E.E. REIS, \\ and D.L. SEVIER
}

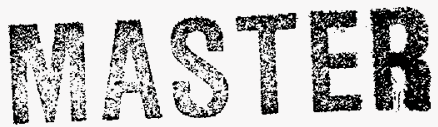

DISTRIBUTION OF THIS DOCIBENT IS UNLIMITED

OCTOBER 1996 


\section{DISCLAIMER}

Portions of this document may be illegible in electronic image products. Images are produced from the best available original document. 


\title{
THE DIII-D RADIATIVE DIVERTOR PROJECT, STATUS AND PLANS
}

\author{
by \\ J.P. SMITH, C.B. BAXI, A.S. BOZEK, E. CHIN, M.A. HOLLERBACH, \\ W.R. JOHNSON, E.J. LAUGHON, D.G. NILSON, † E.E. REIS, \\ and D.L. SEVIER
}

This is a preprint of a paper to be presented at the 12th Topical Meeting on The Technology of Fusion Energy, June 16-20, 1996, Reno, Nevada and to be published in the Proceedings.

tLawrence Livermore National Laboratory

\author{
Work supported by \\ the U.S. Department of Energy \\ under Contract No. DE-AC03-89ER51114
}




\section{THE DII-D RADIATIVE DIVERTOR PROJECT, STATUS AND PLANS}

J.P. Smith

General Atomics

P.O. Box 85608

San Diego, California 92186-9784

(619) $455-3836$

\section{E. Chin}

General Atomics

P.O. Box 85608

San Diego, California 92186-9784

(619) $455-4231$

\author{
G.J. Laughon \\ General Atomics \\ P.O. Box 85608 \\ San Diego, California 92186-9784 \\ (619) 455-2520
}

D.G. Nilson

Lawrence Livermore National Laboratory

c/o General Atomics

P.O. Box 85608

San Diego, California 92186-9784

(619) 455-4144

\author{
C.B. Baxi \\ General Atomics \\ P.O. Box 85608 \\ San Diego, California 92186-9784 \\ (619) 455-3150 \\ M.A. Hollerbach \\ General Atomics \\ P.O. Box 85608 \\ San Diego, California 92186-9784 \\ (619) 455-2770

E.E. Reis
General Atomics
P.O. Box 85608
San Diego, California $92186-9784$
(619) $455-2948$

\author{
A.S. Bozek \\ General Atomics \\ P.O. Box 85608 \\ San Diego, California 92186-9784 \\ (619) $455-4431$ \\ W.R. Johnson \\ General Atomics \\ P.O. Box 85608 \\ San Diego, California 92186-9784 \\ (619) 455-2905

D.L. Sevier
General Atomics
P.O. Box 85608
San Diego, California $92186-9784$
(619) 455-4769 \\ D.L. Sevier \\ P.O. Box 85608 \\ (619) 455-4769
}

\begin{abstract}
New divertor hardware is being designed and fabricated for the Radiative Divertor modification of the DIII-D tokamak. The installation of the hardware has been separated into two phases, the first phase starting in October of 1996 and the second and final phase, in 1998. The phased approach enables the continuation of the divertor characterization research in the lower divertor while providing pumping for density control in high triangularity, single- or double-null advanced tokamak discharges. When completed, the Radiative Divertor Project hardware will provide pumping at all four strike points of a doublenull, high triangularity discharge and provide baffling of the neutral particles from transport back to the core plasma. By puffing neutral gas into the divertor region, a reduction in the heat flux on the target plates will be
\end{abstract}

demonstrated without a large rise in core density. This reduction in heat flux is accomplished by dispersing the power with radiation in the divertor region. Experiments and modeling have formed the basis for the new design. The capability of the DIII-D cryogenic system is being upgraded as part of this project. The increased capability of the cryogenic system will allow delivery of liquid helium and nitrogen to three new cryopumps.

Physics studies on the effects of slot width and length can be accomplished easily with the design of the Radiative Divertor. The slot width can be varied by installing graphite tiles of different geometry. The change in slot length, the distance from the $\mathrm{X}$-point to the target plate, requires relocating the structure vertically and can be completed in about 6-8 weeks. 
Radiative Divertor diagnostics are being designed to provide comprehensive measurements for diagnosing the divertor. Minimal modifications are required to diagnostics for the Phase 1 installation. More extensive diagnostic changes are planned for the Phase 2 installation. These Phase 2 diagnostics will be required to fully diagnose the high triangularity discharges in the divertor slots.

\section{INTRODUCTION}

The physics of the divertor has become a major thrust of current tokamak research. The major issues in the research are reduction in the divertor heat flux to levels manageable by the plasma facing materials, operation of the divertor with core particle and impurity control, and minimization of erosion rates by control of the sputtering. The design of future machines such as ITER rely on development of innovative solutions to these challenging problems. The DIII-D program has been developing a new divertor, the Radiative Divertor Project (RDP), utilizing radiation to distribute the heat flux and reduce energetic particle impingement to the strike plate. At the same time, baffle structures and cryo pumps are provided to provide core particle and impurity control. The design is based on experimental data from the existing open DIII-D divertor and from code calculations that model the divertor and scrape-off layer plasma. Expermimental results have shown a reduction of the heat by radiation in the divertor

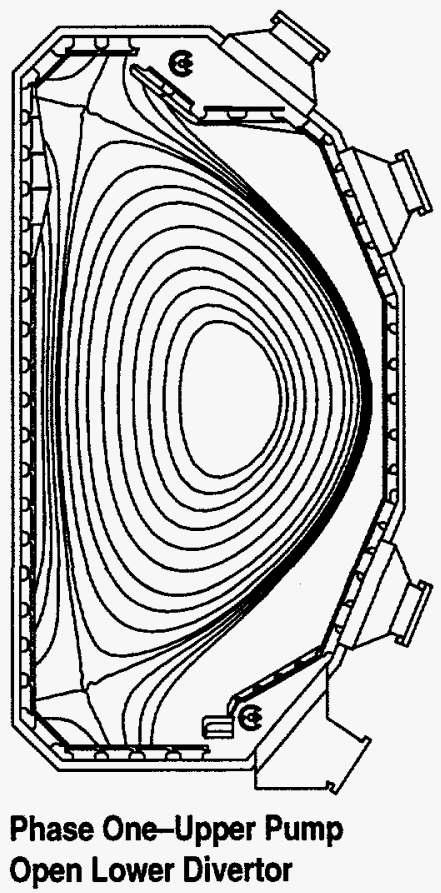

region to be highly efficient. The new divertor structure will reduce the effects of gas puffing on the plasma core, allow independent control of divertor and core plasma parameters and provide particle control in high triangularity plasma operations. Ideally the new structure will also influence the distribution of radiation, but this has not been conclusively determined either by modeling or experiment. The shape of the RDP was determined experimentally, via a systematic study led by Lazarus, ${ }^{1}$ concluding that a high triangularity shape is necessary for high performance discharges.

When the project is completed, DIII-D will have a baffled, double null divertor structure with pumping at all four strike points (Fig. 1). The hardware is built around a double-null, high triangularity plasma shape, demonstrated to have high performance. Flexibility is a key feature of the design. The capability will exist to run either single or double null experiments with the RDP structure as well as easily modifying both the slot width and length. The initial geometry of the divertor structure is a slot type divertor with an initial slot length (the distance from the X-point to the target plate) of $23 \mathrm{~cm}$. The new divertor hardware enables research to continue toward the DIII-D program goal of integrated long pulse demonstration of a well confined high-beta divertor plasma with non-inductive current drive.

The design is completed and fabrication is in progress for Phase 1 of the new RDP structure (Fig. 1). The instal

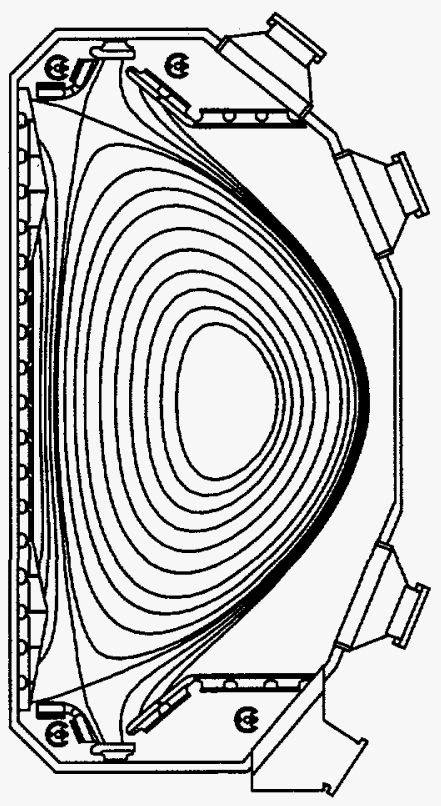

Full RDP Installation

Fig. 1. The Radiative Divertor installation in DIII-D (a) Phase 1 with upper outer baffle and cryopump. (b) The full RDP installation with active pumping and baffling at all four strike points. 
lation of the RDP has been divided into two phases, installation of the outer baffle for the upper-outer divertor leg in fall of 1996 with the balance of the hardware installed in 1998. This is to (1) relieve budget pressure on the DIII-D project, (2) provide additional experimental time in the lower divertor. The implementation of the RDP requires significant changes to the divertor diagnostics to enable views past the baffle structures into the slot region. With the installation of the upper-outer structure only, continued divertor characterization can continue in the lower divertor, where an excellent divertor diagnostic set exists.

\section{MECHANICAL DESIGN}

The design of the RDP utilizes engineering and technology developed in the successful DIII-D Advanced Divertor Program (ADP) which consisted of a toroidally continuous gas baffle and cryo condensation pump. In the ADP, divertor pumping and density control was demonstrated in $\mathrm{H}$-mode plasmas utilizing the liquid helium cooled cryopump. The graphite tile design developed in 1987 for the DIII-D divertor will continue to be used in the RDP.

The complete in-vessel hardware consists of six toroidally continuous baffles and four cryopumps, with near updown symmetry. The lower baffles and cryopumps are pictured in Fig. 2. Outer and private flux baffles are created by mounting graphite tiles to new toroidally continuous support panels. The outer baffle reduces the core ionization current caused by puffing in the divertor, a factor of seven. The baffles on the inner wall are composed of thick graphite tiles mounted to the vessel wall. They provide additional baffling of the neutrals, with the core ionization current reduction factor increased to nine.

Beneath the outer and private flux baffles of the Phase 2 RDP will be liquid helium cooled cryopumps which provide nearly $100 \mathrm{~m}^{3} / \mathrm{s}$ pumping speed. These cryopumps will provide density control by pumping at all four strike points of a double null plasma. This will be the first time in a tokamak where a study of inner versus outer strike point pumping can be conducted. Three of the pumps will be new, while the existing cryopump will remain in operation under the lower outer baffle.

\section{A. Structure}

The main structural elements of the new divertor are four toroidally continuous water cooled panels attached to the vessel wall with a set of supports spaced every 15 degrees (Fig. 3). The design concept was chosen for its strength and reduction of electric potentials during

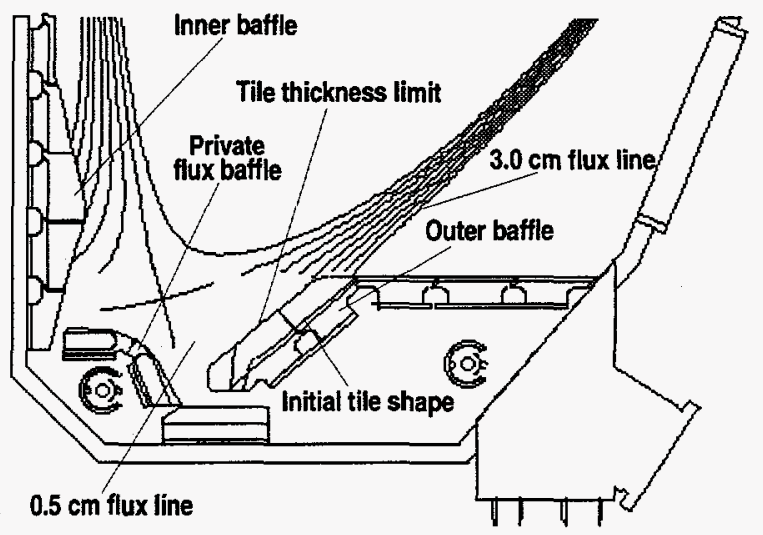

Fig. 2. Cross section of lower RDP structure. Limits of the tile thickness are shown with flux lines.

disruptions. In addition, the ability is maintained to bake the structure inductively, driving current in the panels by running AC currents in the ohmic heating coils. This is the method presently used to bake the vacuum vessel. Inconel 625 was chosen as the panel material for its high resistivity and good strength.

The primary loads on the structure are halo current induced. The halo current driven in the scrape off plasma enters the structure, flows in the panels and to the vessel through the set of supports. This current is crossing the toroidal field resulting in large loads. Based upon measured DIII-D data, a halo current equal to $20 \%$ of the pre-disruption plasma current with a 2:1 peak to average toroidal asymmetry was applied in the analysis of the structure. The maximum plasma current of DIII-D after the RDP is installed is $3 \mathrm{MA}$ with the peak of the halo current lasting $2 \mathrm{~ms}$. The resultant vertical loads are reacted through the supports to the vessel wall while the radial loads are reacted primarily by the hoop strength of the rings. A set of current shunts will monitor the halo currents in the structure. In addition, toroidal currents are driven in the rings during a disruption by the change in vertical magnetic field, but the resultant loads are small compared to the halo current induced loads.

The panels are connected to the vacuum vessel cooling system, which provides $30^{\circ} \mathrm{C}$ water during plasma operations and hot air during vessel baking. The Inconel panels reach a temperature of $350^{\circ} \mathrm{C}$, the same temperature as the outer wall of the vacuum vessel. The hot air serves to distribute the heat in the vacuum vessel during the bake. During operation a total of $72 \mathrm{gpm}$ flows through the system with an average temperature rise of $-20^{\circ} \mathrm{C}$ with a $38 \mathrm{MW}$, single null divertor plasma. The water flow path is single pass, with the top and bottom divertor rings fed off separate manifolds. 


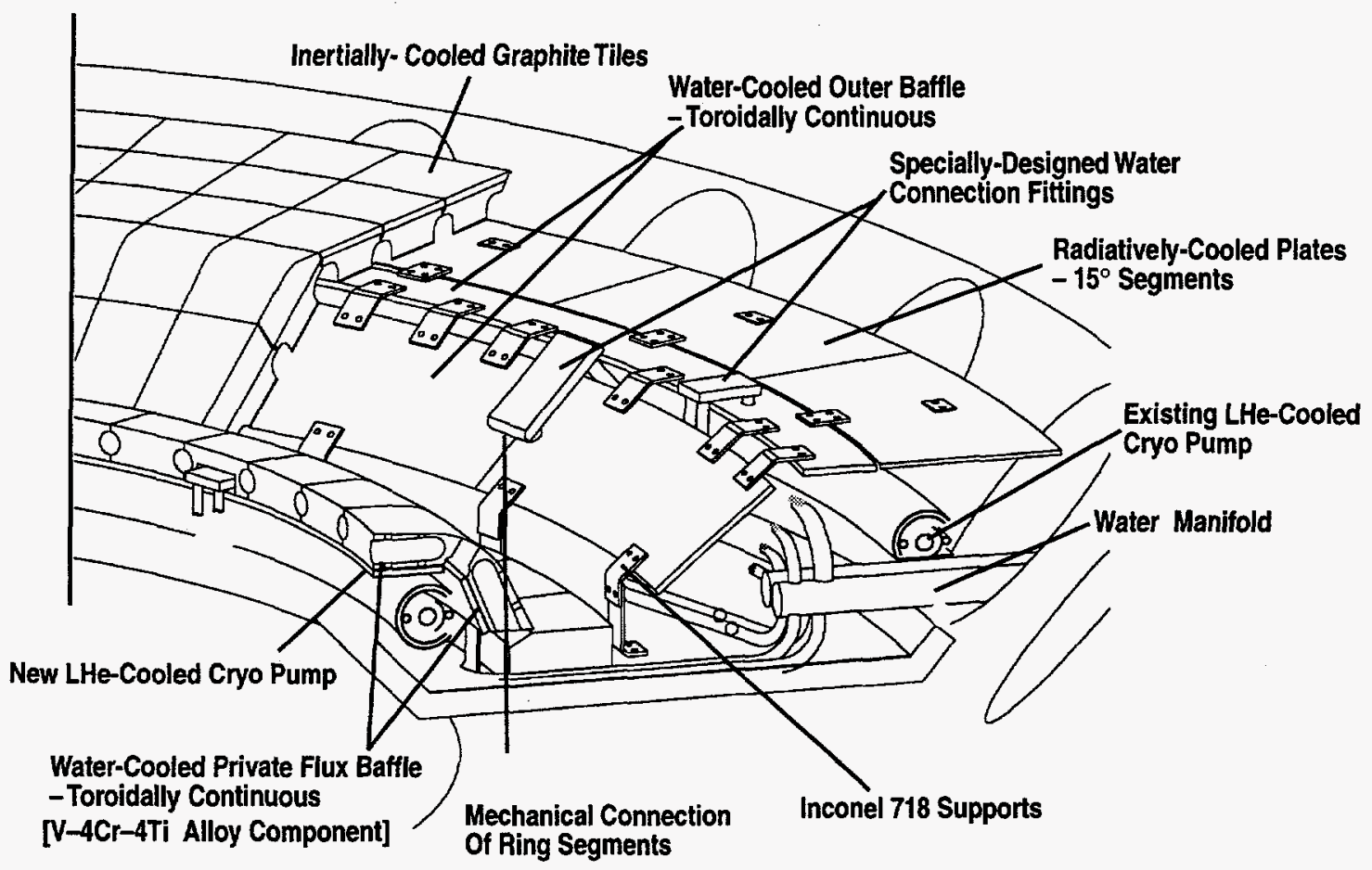

Fig. 3. Radiative Divertor structural rings with supports. Graphite tiles are bolted to support rings.

Each water cooled panel is manufactured in four segments, bolted and pinned together in the vessel (Fig. 4). The panels' coolant channels are joined by specially designed manifolds that can be welded completely from the front side. The panel segments are made by joining two sheets of Inconel 625 together after a slot has been machined in each, to form the water coolant channel. The panels are welded together using a combination of TIG and resistance seam welding. The TIG weld provides the perimeter seal weld and the resistance seam weld makes the structural connection between the sheets. This combination was chosen to minimize distortion. A prototype panel has been manufactured to evaluate the production method and to quantify the weld distortion. A 90 degree segment was made. The distortion was minimal and easily corrected with cold forming. Production of the upper outer baffle rings is in progress. Two complete rings, one conical and one flat are being produced.

Designing a structure that would provide the capability of improving the physics understanding of divertors was paramount to the success of the RDP. The ability to change both the slot width (the shaping of the tile surface relative to the magnetic field lines) and the slot length was incorporated into the design. The slot width can be modified by changing the thickness of the tiles. With the field lines measured by their distance out into the SOL from the separatrix at the midplane. The base installation has the $1.25 \mathrm{~cm}$ to the $3 \mathrm{~cm}$ field lines striking

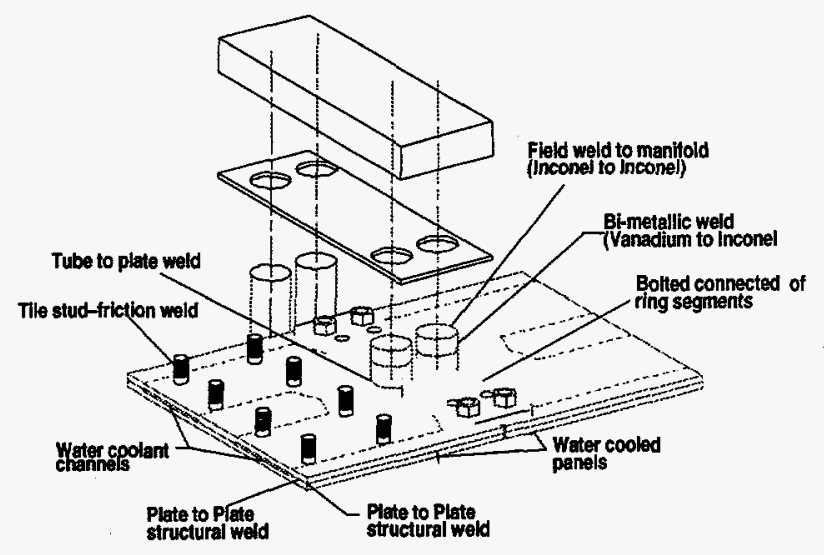

Fig. 4. The design of the water cooled structure joint. The four segments of the ring are bolted and pinned together, and the welding performed from the front surface only.

the outer baffle (Fig. 2). A new set of tiles can be created with the range of field lines at the strike point (down stream) end of the baffle being the 1-2 $\mathrm{cm}$ field lines and the upstream side varying from the $2-3 \mathrm{~cm}$ field lines. A set of tiles can be installed during a vent in about one week once the shape has been determined and the tiles manufactured. The slot length is capable of being modified from the nominal $23 \mathrm{~cm}$ to 33 or $43 \mathrm{~cm}$. This is accomplished by vertically raising the existing water cooled panels, changing the supports and adding additional water cooled panels. It is believed that this modification can be accomplished during a 6 week vent. 
Capability for these modifications have been incorporated in the water system design. Sufficient water system capacity and connection points have been included for these modifications at a later time.

\section{B. Tiles}

The basic design used for the existing divertor tiles will be maintained for the RDP. These tiles, inertially cooled graphite, are mechanically attached to the water cooled vessel wall or the water cooled support panels. The existing tiles have been in operation since 1987 without failure. The tile heat flux capability is $5 \mathrm{MW} / \mathrm{m}^{2}$ for $5 \mathrm{~s}$ or $3.8 \mathrm{MW} / \mathrm{m}^{2}$ for $10 \mathrm{~s}$ limited by the peak surface temperature of $1200^{\circ} \mathrm{C}$. A reduction in divertor heat flux by a factor of 2 is anticipated to be required for full power (38 MW) operation. This reduction has already been demonstrated in the radiative mode of the present open divertor. When the thermal limit of the tiles are reached, it is planned to replace the graphite tiles where necessary with carbon fiber composite (CFC) tiles. These CFC tiles will have greater thermal conductivity and will reduce the peak surface temperature. Graphite is used because it is a low cost material that makes the changes in baffle shape affordable; the estimated cost for full coverage of CFC tiles exceeds $\$ 2.0 \mathrm{M}$ a factor of ten more than with graphite.

The tile thickness to achieve the previously mentioned flexibility, ranges from 5 to $10 \mathrm{~cm}$ with the lower limit set by thermal stresses in the tiles and the upper limit governed by stresses created by halo current forces. The poloidal force from the halo current crossing the toroidal field is reacted by the frictional force generated by the tile holddown load for the $5 \mathrm{~cm}$ tiles. As the thickness increases, other methods of reacting the shear load are required and designs have been created to react these loads. The primary method is with the use of a shear key reacting the load back to the tile hold down studs.

\section{Cryocondensation Pumps}

The cryopump is also electrically continuous in the toroidal direction to minimize the potential for electrical breakdown in the low density plasma existing underneath the baffles. The strength of the resulting hoop is also utilized in reacting the loads resulting from a disruption. The pumping surface consists of a $2.5 \mathrm{~cm}$ diameter Inconel tube cooled by sub-cooled liquid helium at $4.3 \mathrm{~K}$. The helium tube is grounded only at the vessel feedthrough and is electrically isolated from the surrounding liquid nitrogen cooled shield. The liquid nitrogen shield forms the primary structural component for the pump. It is laser cut from $8 \mathrm{~cm}$ diameter, $1.5 \mathrm{~mm}$ wall tubing. Although it is of the same basic design as the existing ADP pump, the compact area under the private flux baffle required a different support system to limit the deflections from disruption induce loads (Fig. 5). The new support limits the vertical deflection of the pump while providing radial flexibility to accomodate the thermal contraction when cooled. The feed lines will utilize a vertical port, requiring a $2 \mathrm{~m}$ long vertical run of concentric tubing. A concern about the flow stability with two phase helium flow in the vertical column led to a test of the new feed geometry. In the test, the pump performance was measured and compared to data on the existing pump. No detectable loss of performance was measured in the test and the design was confirmed.

The RDP Phase 1 upper outer pump design has been completed and the pump is being manufactured. The tubing for the shells of the pump has been rolled and the pumping aperatures are presently being laser cut. After cutting, the liquid nitrogen flow tubes will be welded on prior to flame spraying copper stripes on the outside of the nitrogen shell to enhance thermal conductivity. The support hardware is also presently being manufactured.

Upgrades to the cryosystem hardware are required to supply cryogens for the additional pumps. Eventually, two new cryostats will be installed in the machine hall with one presently being manufactured and assembled for Phase 1. The cryostats serve to sub-cool the liquid helium prior to entrance into the pump. The cryostats are connected to the cryo supply system via coaxial flexible transfer lines. A similar line was used in the ADP. The cryo system is isolated from the tokamak with $30 \mathrm{kV}$ d.c. breaks to maintain electrical safety during machine operation. An upgrade to the distribution box for the system is required to supply cryogens to the three new Phase 2 pumps. The box has been designed and production has started. When fully operational in Phase 2, additional compressor capacity or a gas surge tank will be required to handle the gas load from regeneration of the pump between shots.

\section{Vanadium in the RDP}

The private flux baffle of the upper divertor will be manufactured from vanadium alloys as part of an effort by General Atomics to further the development of low activation alloys for use in fusion power plants. Vanadium alloys have been identified by the Fusion Materials Program of DOE as a leading low activation material for their high temperature capabilities and irradiation stability. The usage of vanadium in DIII-D will demonstrate the development of processing and manufacturing methods for vanadium alloys and verify the in-service behavior of 


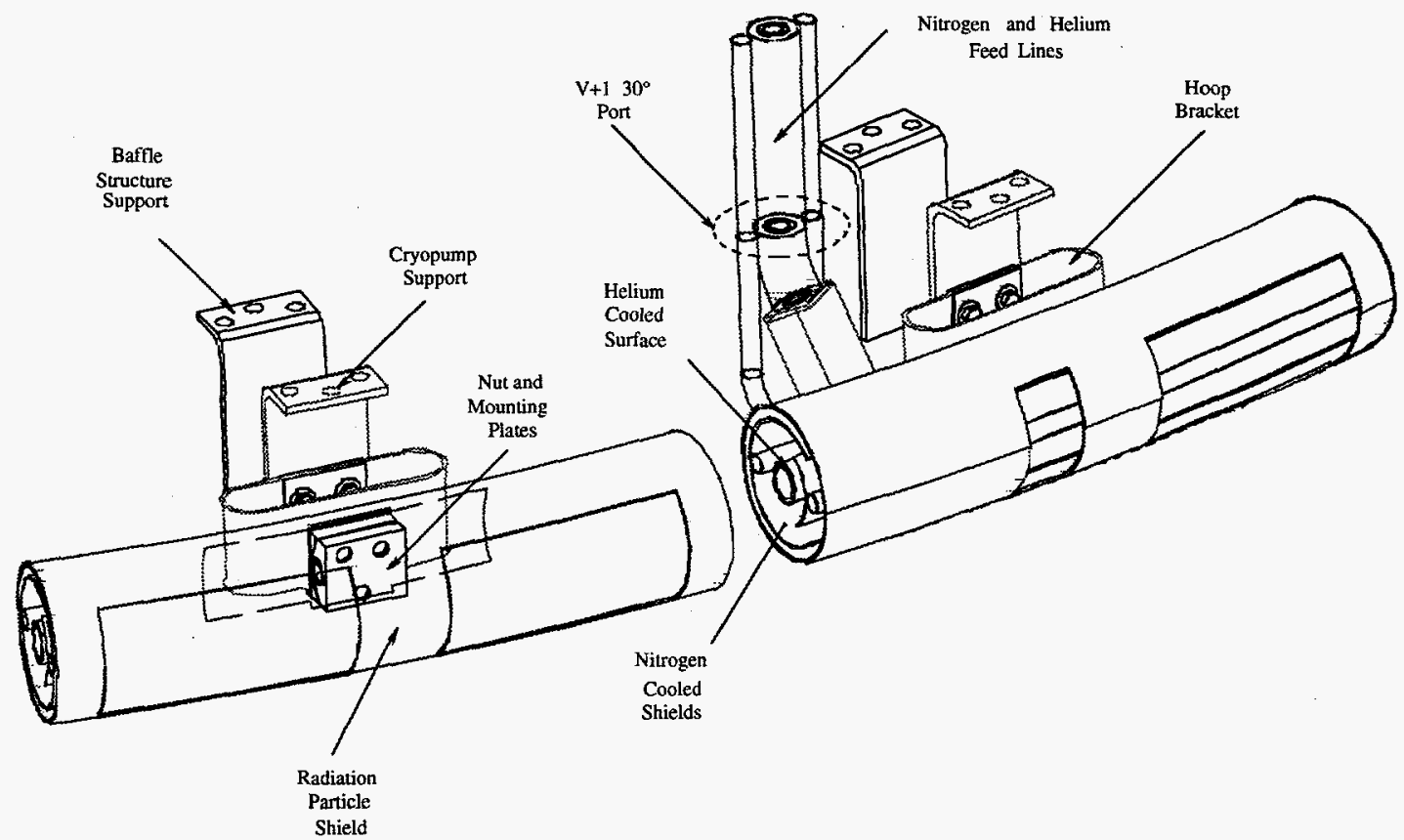

Fig. 5. Cryopump design, with supports and feedlines.

vanadium alloys in a tokamak. Compatibility of vanadium alloys with the tokamak environment, particularly impurity pick-up and subsequent embrittlement, is a concern and the exposure of components will aid in answering these questions. In the area of design and manufacturing of components from vanadium alloys, little has been done, particularly in the area of joining. The RDP work is designed to develop preliminary engineering design data and manufacturing experience for vanadium alloys as a necessary first step toward the qualification of the material for reactor use.

The production of the material has started and research on welding is underway. A companion paper ${ }^{2}$ at this conferance desribes the program in detail along with the progress.

\section{E. Diagnostics}

The installation of the RDP requires modification to many existing diagnostics as well as new diagnostics. A basic set of diagnostics is required to measure the reduction in power to the target plates and to gather information to allow for an understanding of the physical processes involved in the disipative divertor experments. The RDP impacts divertor diagnostics in several ways. The first is the redistribution of diagnostic locations to accomodate new diagnostics and feedthroughs for the RDP structure, cryopumps and new diagnostics. Many diagnostics are being relocated and in some cases, multiple diagnostics are combined at single port location. Other diagnostics are being moved to improve the view of the plasma. Many existing diagnostics need to be modified to be able to view down into the divertor slots, particularly in the longer slot length options.

Phase 1 of the RDP requires minimal diagnostic modification. Several diagnostics, such as the soft X-ray system and bolometers will be moved to new locations. New diagnostics that will be installed with the Phase 1 hardware are halo current monitors and magnetics arrays (Fig. 6). The halo current monitors are a shunt to monitor the current flowing in the supports of the RDP structure. The magnetics are mounted directly on the RDP structure to allow better $\mathrm{X}$-point positioning. Pick-up coils to mreasure $B_{\theta}$ and saddleloops for measuring $B_{\perp}$ will be installed.

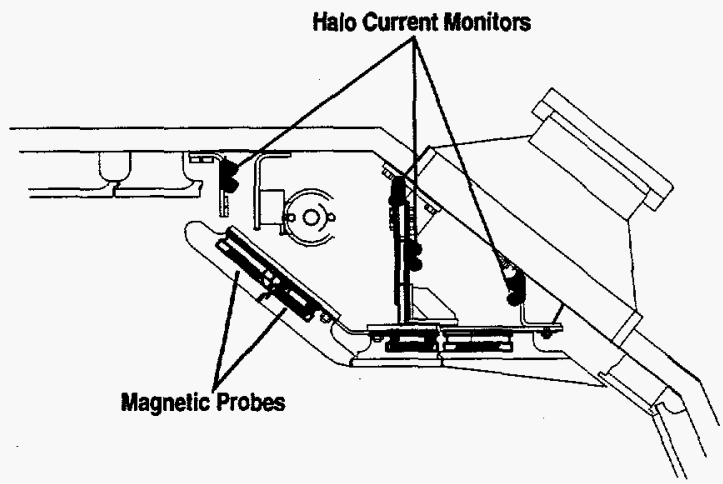

Fig. 6. Location of magnetic probes and halo current monitors on the RDP structure.

Upon the completion of the project, there will be diagnostics to evaluate power balance, impurity transport, 
erosion and sputtering, scrape off layer and divertor plasma parameters, and measurement of neutral gas density. A complete report of the diagnostics plans can be seen in Ref. [3].

\section{F. Installation}

The installation of the upper outer baffle assembly will occur October-December 1996. Included in this work is the installation of the cyropump under the baffle. The cryo system will also be upgraded with a new cryostat servicing the pump along with a new distribution box and transfer line. Preparation of the hardware outside of the vessel will minimize the amount of work required in the vessel and thus the duration of the vent. A tooling plate will also be used to aid in the outside vessel pre-assembly of the structure. The structure will also be aligned to the existing vacuum vessel ports utilizing this tooling plate. This plate will also locate the studs on the vessel for the supports. Sequencing of the installation has been planned to coordinate the installation of the diagnostics in conjunction with the structure. The installation of the upper structure requires a special work platform be installed about $0.5 \mathrm{~m}$ from the floor of the vessel. After the installation of the platform, work on the lower divertor will be difficult, thus plans have been made for lower divertor work to be completed before the RDP work begins.

\section{CONCLUSION}

The radiative divertor for DIII-D has been designed. It provides the density control needed for continued advanced tokamak research as well as baffling for neutral gas injected in the divertor region to enhance the radiated power in the divertor leg. It is flexible to evolve with the physics understanding of the radiative divertor and particle control. Fabrication is in progress and installation to be completed in December of 1996. Operation of the RDP will begin in January of 1997.

\section{ACKNOWLEDGMENT}

Work supported by the U.S. Department of Energy under Contract Nos. DE-AC03-89ER51114 and W-7405ENG-48.

\section{REFERENCES}

1. E.A. Lazarus, A.W. Hyatt, T.H. Osborne, Bull. Am. Phys. Soc. 38 (1993) 1936.

2. J.P. Smith, et al., "Manufacturing Development of low Activation Vanadium Alloys," this conference.

3. D.G. Nilson, et al., "Diagnostics for DIII-D Radiative Divertor," Proc. of the 16th Symposium on Fusion Energy, Champaign-Urbana, Illinois, 1995 to be published. 